\title{
Diversity of Dickeya Strains Collected from Pineapple Plants and Irrigation Water in Hawaii
}

W. S. K. Sueno, Plant and Environmental Protection Sciences, G. Marrero, Molecular Biosciences and Bioengineering, and A. S. de Silva, D. M. Sether, and A. M. Alvarez, Plant and Environmental Protection Sciences, University of Hawaii, Honolulu 96822

\begin{abstract}
Sueno, W. S. K., Marrero, G., de Silva, A. S., Sether, D. M., and Alvarez, A. M. 2014. Diversity of Dickeya strains collected from pineapple plants and irrigation water in Hawaii. Plant Dis. 98:817-824.

Bacterial heart rot caused by a yet undetermined species of Dickeya was first observed in December 2003 in Oahu, HI, on a pineapple cultivar (Ananas comosus 'PRI 73-114') recently imported from Central America. Identical symptoms were later seen in the same plantation in fields that had been planted with propagules from the Philippines. Dickeya strains isolated from symptomatic plants and irrigation water collected over subsequent years were identified using bacteriological tests and partial $16 \mathrm{~S}$ ribosomal DNA sequencing and characterized using repetitive sequence-based polymerase chain reaction (rep-PCR) with the BOXA1R primer (BOX-PCR), pathogenicity on pineapple leaves, and reactivity with two monoclonal antibodies (MAbs). Strains exhibited variability in pathogenicity and in

reactivity with MAbs. BOX-PCR separated the plant-isolated Dickeya strains into seven haplotypes that were placed into four fingerprint groups (A to D). Strains from the A and B groups were isolated from the Central American stocks, whereas strains in the D group were identified from Philippine material. Strains from the C group were isolated from both planting materials. Most strains from water sources were placed into three haplotypes that loosely formed group E. BOXPCR polymorphisms between the Dickeya strains isolated from foreign pineapple plants, a local collection of Dickeya strains, and strains from the plantation's water sources support the possibility that at least two separate introductions of genetically distinct strains occurred via imported planting stocks.
\end{abstract}

Pineapple (Ananas comosus (L.) Merr.) is the third most important fruit crop, after banana and citrus, in tropical and subtropical regions of the world (20). In 2007, Hawaii produced about 172,000 tons of the more than 18 million tons of pineapple fruit produced worldwide (4). Pineapple is a perennial, herbaceous monocotyledon that is typically planted at densities of 60,000 to 90,000 plants/ha. Fields are planted with vegetatively propagated planting material such as crowns from atop the fruit, slips from the fruit peduncle, or suckers from the base of the stem (7). The first crop, referred to as the plant crop, requires 14 to 20 months to produce a single fruit per plant. After fruit harvest, the mother plants decline and produce one to two suckers, called ratoons, at the stem base. The next cropping cycle (the first ratoon crop), requires 12 to 15 months to produce fruit. Second and third ratoon crops are uncommon in Hawaii because of the build-up of diseases and pests. Clonal propagation and relatively long production cycles of pineapple perpetuate latent pathogen infections and contribute to disease and pest increase (21).

Members of the genus Dickeya (comprising strains formerly classified as Erwinia chrysanthemi and, later, Pectobacterium chrysanthemi; 5) cause soft rot diseases on plant species in at least $35 \%$ of angiosperm plant orders $(1,11)$. The genus was originally subdi-

Corresponding author: A. M. Alvarez, E-mail: alvarez@ hawaii.edu

Current address of W. S. K. Sueno: U.S. Department of Agriculture, Honolulu, HI 96819.

Current address of D. M. Sether: U.S. Fish and Wildlife Service, Honolulu, HI 96850.

This material was made possible, in part, by a Cooperative Agreement from the United States Department of Agriculture's Animal and Plant Health Inspection Service (APHIS). It may not necessarily express APHIS' views.

Accepted for publication 9 January 2014.

http://dx.doi.org/10.1094/PDIS-03-13-0219-RE

(C) 2014 The American Phytopathological Society vided into six accepted species: Dickeya chrysanthemi, D. paradisiaca, $D$. dadantii, $D$. dianthicola, $D$. dieffenbachiae, and $D$. zeae (24). Brady et al. (2) used phylogenetic analyses to reclassify the genus, eliminating $D$. dieffenbachiae and dividing $D$. dadantii into two subspecies, dieffenbachiae and dadantii. Recently, the addition of a new species, D. solani, has been proposed to encompass biovar 3 strains of the predominant blackleg and slow wilt pathogen of potato in Europe $(25,27)$.

As with other pathogens, challenges exist in the detection and identification of Dickeya spp. that complicate regulatory efforts to prevent their spread on commercially traded propagules. The development of a rapid detection and identification assay using loopmediated isothermal amplification technology has recently been described and evaluated for the blackleg and potato wilt pathogen P. atrosepticum (9). This assay successfully amplified $P$. atrosepticum without cross-reacting with the closely related blackleg pathogens $P$. carotovorum and Dickeya spp. on greenhouse and fieldgrown potato plants exhibiting blackleg disease. The specificity of this assay and its portability make it a useful diagnostic for detecting latent infections; however, the assay was not evaluated for use with latently infected potato seed tubers. Such a diagnostic tool would be practical for evaluating not only potato propagules but also a range of commercially traded propagules of economic importance (such as pineapple) because Dickeya spp. have overlapping host ranges, elicit similar symptoms in the same hosts, and are morphologically indistinguishable. Methods that not only identify but also discriminate introduced populations of the pathogen from local populations of the same species also are highly desirable.

In early 2003, a commercial pineapple plantation on the island of Oahu imported pineapple slips of a low-acid cultivar, 'PRI 73114', from Costa Rica and Honduras. During the course of the growing season, some plants began to exhibit browning and watersoaking of maturing leaves that started at the base of the leaf and progressed toward the leaf tip as well as into the stem. The apical portions of the stems became soft, often leading to total collapse of the plant. Spatial analyses of disease incidence in one of the affected fields indicated an initial random pattern of symptomatic plants. Additionally, neighboring fields planted with locally produced but genetically different propagative material did not show 
any symptoms of bacterial heart rot. Taken together, these observations suggested two early scenarios: the arrival of a new pathogen on the imported stocks or the introduction of a pineapple clone susceptible to local populations of Dickeya.

Using a combination of bacteriological tests, carbon source utilization profiling (Biolog, Inc.), and 16S ribosomal DNA (rDNA) sequence analysis, the causal agents of this outbreak were identified as E. chrysanthemi (subsequently reclassified as Dickeya spp.) and the disease was identified as bacterial heart rot $(6,29)$. In late 2003 , the field from which the potentially introduced pathogen was isolated was placed under quarantine by state and federal regulatory officials and the plants were pulled up and destroyed.

After this initial report, bacterial heart rot symptoms were observed in other fields planted with imported stock; in these cases, from the Philippines. This prompted a more comprehensive survey of the original Oahu plantation and an additional survey of a plantation on Maui planted with a related pineapple accession that was grown exclusively from Hawaiian propagules. The purpose of this study was to collect and characterize Dickeya strains from infected pineapple plants and irrigation water sources within the fields to begin understanding the origin of the pathogens infecting these plants.

\section{Materials and Methods}

Bacterial isolations and identification of Dickeya strains. Plant and water samples from two commercial pineapple plantations on the islands of Oahu and Maui were collected between 23 December 2003 and 11 June 2008. These consisted of 29 sets of tissues from two pineapple cultivars, 'PRI 73-114' and 'PRI 73050', and 10 sets of irrigation water samples obtained from 11 sources (five irrigation ditches and six reservoirs) in and around the pineapple fields. A set refers to a group of samples collected on the same date. A sample refers to a single tissue specimen or tube of water taken for analysis. Most plant samples obtained from PRI 73-114 exhibited the typical water-soaking and odor associated with bacterial heart rot. Parent material for these samples originated from Costa Rica, Honduras, or the Philippines. All fields sampled on the Oahu plantation had plant crops that exhibited bacterial heart rot symptoms. Characteristic symptoms were not observed in PRI 73-050 plants which were grown on the Maui plantation; therefore, samples consisted of leaf material displaying other symptoms such as leaf spotting and tip dieback. Irrigation water samples were collected in 50-ml Falcon tubes directly from the water sources or by cooperators in the field, and hand carried to the laboratory for analysis. All samples were processed within a day of receipt. Bacterial isolations were made on Miller-Schroth medium (MS) and a medium containing tetrazolium chloride (TZC), as previously described (6). Irrigation water subsamples of $10 \mathrm{ml}$ were passed through 47 -mm-diameter, $0.45-\mu \mathrm{m}$ mixed cellulose ester membrane filters (Millipore), and the filters were then placed face up onto the surface of MS medium plates to allow bacterial colony development. Presumptive identification of Dickeya strains was done using bacteriological tests (including the potassium hydroxide test for gram reaction, glucose fermentation using an oxidation/fermentation (OF) basal medium supplemented with glucose, and pit formation on crystal violet sodium polypectate medium), metabolic profiling using the Microbial Identification System (Biolog Inc.), and polymerase chain reaction (PCR) using the ADE1/ADE2 primer set described by Nassar et al. (16), all as previously described (6). A subsample of presumptive Dickeya strains also were confirmed to genus level by $16 \mathrm{~S}$ rDNA sequence analysis using primers fD1 and rP2 (30).

Monoclonal antibody generation and indirect enzyme-linked immunosorbent assay. Monoclonal antibodies (MAbs) were generated against strain A5292 isolated from a pineapple plant in the early stages of the epidemic using protocols standardized for our laboratory (19). MAb clones19c2g4 and 97c1f8 were selected for further study based on reactivity against a panel of Dickeya strains, other members of the family Enterobacteriaceae (including $\mathrm{Er}$ winia and Enterobacter spp.), and other nonrelated bacterial spe- cies. Pure, formalinized cultures were used in all enzyme-linked immunosorbent assay (ELISA) assays. Indirect ELISA using 5aminosalicylic acid as the peroxidase substrate was performed as previously described (6). Positive wells developed a dark brown color and final optical density at $450 \mathrm{~nm}$ readings were taken on a MicroStation plate reader using KC4 Microplate Data Analysis Software (Bio-Tek Instruments Inc.). Strains were considered positive if ELISA values were at least two standard deviations above the averaged values of the negative control wells for that run.

Repetitive sequence-based PCR genomic fingerprinting. DNA fingerprints of the Dickeya strains isolated during this study as well as four reference strains were generated using the BOXA1R primer (28), as previously described $(6,10)$. Reference strains CFBP 1278 (A5417), CFBP 1272 (A5421), CFBP 2052 (A5422), and CFBP 6466 (A5423) were obtained from the Collection Française de Bactéries Phytopathogenès (CFBP), Beaucouzé, France. They represented Dickeya spp. previously isolated from Malaysian pineapple in 1961 (CFBP 1278 and CFBP 1272) as well as strains classified as Dickeya zeae isolated from pineapple from Martinique in 1991 (CFBP 6466) and the type strain of that species from Zea mays from the United States in 1970 (CFBP 2052). Gels were run on a Gibco BRL model H4 horizontal gel apparatus (Life Technologies) for $5 \mathrm{~h}$ at $105 \mathrm{~V}$. Strain patterns were compared visually, using standard strains in each gel run for band comparisons. Each unique banding pattern generated by BOX-PCR was considered a haplotype. Haplotypes were initially placed into one of five Dickeya fingerprint groups (A to E) based on visual similarities. Fingerprints were further analyzed using the GelCompar II software package (version 3.5; Applied Maths). Band positions were normalized with respect to the $1-\mathrm{kb}$ standard. The dendrogram was constructed by similarity and clustering analyses using the cosine coefficient and the unweighted pair grouping method with arithmetic mean algorithm with optimized parameters ( $2.5 \%$ optimization, $1 \%$ curve smoothing).

Pathogenicity tests. Inoculation of attached pineapple leaves was done using nonsymptomatic PRI 73-114, as previously described (6). At least two fully expanded leaves were inoculated with each strain. After a 72-h incubation, reactions were scored visually on a scale of 0 (nonpathogenic) to 3 (highly virulent), where 0 represented a leaf exhibiting a light tan, discrete necrotic area around the leaf incision and 3 was a typical bacterial heart rot lesion (puffy, water-soaked, extending away from the point of inoculation). Reactions scoring 1 or 2 were visually similar to those reactions rated a 3 but exhibiting less symptom development. Individual leaf scores were averaged for each strain tested, and these averages were then used to determine relative virulence. Strains considered nonpathogenic had average leaf inoculation scores of 0.0 to 1.0 . Generally, these strains did not produce a typical bacterial heart rot lesion. Strains considered weakly virulent had scores between 1.1 and 1.7. These strains occasionally caused discrete leaf lesions but the results were not consistent between leaves. Highly virulent strains had scores between 1.8 and 3.0 and generally caused a spreading lesion on most of the inoculated leaves.

\section{Results}

Bacterial isolations. In all, 103 plant samples were collected from 48 separate blocks in 28 different fields at the two plantations. In total, 94 Dickeya strains were isolated from plant material from 12 of the sampled fields, all from the Oahu plantation. No Dickeya strains were isolated from samples of hybrid PRI 73-050 from the Maui plantation. Twenty-one representative strains of Dickeya were used for ELISA, pathogenicity tests, and BOX-PCR comparisons (Table 1).

During the same time period, Dickeya strains were isolated from 11 irrigation water samples that originated from four sources: three irrigation ditches on Oahu and Maui and one reservoir on Oahu. In most cases, few suspect Dickeya colonies were found after filtration and enrichment. However, in one set, numerous suspect colonies were found in a reservoir sample. Colony BOX-PCR was performed on the individual colonies, and a subsample of those 
strains possessing different haplotypes were purified and characterized. Eleven strains from six water samples representing the various identified haplotypes were used for phenotypic and genotypic comparisons (Table 1).

Genotypic diversity (BOX-PCR fingerprint analysis). During the initial bacterial heart rot outbreak in 2003-04, four Dickeya haplotypes were identified from planting stock that originated from Costa Rica and Honduras. These strains were placed into three BOX-PCR fingerprint groups (designated A, B, and C) based on visual banding patterns. Group A consisted of strains exhibiting a single haplotype with doublets at 2.0 to 1.9 and 1.8 to $1.7 \mathrm{~kb}$. Group B strains also possessed a single haplotype with bands at approximately 2.8 and $2.6 \mathrm{~kb}$ and a strong band near $1.4 \mathrm{~kb}$. One of these strains was selected for further studies. The majority of group $\mathrm{C}$ strains were of one haplotype (C1) possessing a single band at $2.6 \mathrm{~kb}$, a doublet at 2.1 to $2.0 \mathrm{~kb}$, and a band at $1.8 \mathrm{~kb}$ (Fig. 1, lanes 11 and 12). Two strains in group $C$ represented an additional haplotype $(\mathrm{C} 2)$ and were very similar to the $\mathrm{C} 1$ haplotype except for a single band at $2.0 \mathrm{~kb}$, an extra band at approximately $1.4 \mathrm{~kb}$, and a band at approximately $525 \mathrm{bp}$ (Fig. 1, lane 13).

An additional fingerprint group (designated D) consisting of three haplotypes (D1, D2, and D3) contained strains isolated from 2006 to 2008 from slips collected from mother plants that originated in the Philippines (Fig. 1, lanes 14 to 25). All group D haplotypes had several bands in common: a band doublet at 2.6 to $2.4 \mathrm{~kb}$; strong bands at approximately 950,850 , and $750 \mathrm{bp}$; a band at approximately $500 \mathrm{bp}$; and a band at approximately 200 bp. Haplotype D1 always had a doublet at approximately 750 to $725 \mathrm{bp}$ and a doublet at approximately 450 to $400 \mathrm{bp}$. Haplotype D2 had weak bands at approximately $1.7,1.2$, and $1.1 \mathrm{~kb}$. Haplotype D3 was similar to D2 except for the addition of a strong band at $350 \mathrm{bp}$.
Most Dickeya strains isolated from the irrigation water sources represented haplotypes that did not match those in groups A to D. Those with similar but not necessarily identical fingerprints were placed in a separate group, designated E (Fig. 2, lanes 12 to 20). Fingerprints from two strains (A5277 and A5648; Fig. 2, lanes 11 and 21 , respectively) recovered from one of the ditches on Oahu exhibited unique banding patterns that did not resemble Dickeya haplotypes found elsewhere in the study and remained unclassified using this scheme. The only Dickeya strains isolated from the pineapple plantation on Maui during the survey were from sample W4 (Fig. 2, lanes 17 and 18).

The dendrogram of the BOX-PCR fingerprint patterns supported the initial haplotype designations assigned by visual analysis (Fig. 3). Similarities within haplotypes isolated from pineapple plants were high; in most cases, strains of the same haplotype exhibited 97\% similarity or higher. Likewise, fingerprints generated for the same strain on different gels (Fig. 3, indicated by a number in parenthesis following the strain designation) exhibited reproducible banding patterns. Dickeya strains from Hawaii pineapple plants clearly clustered separately from Dickeya strains from irrigation water. All were different from the D. zeae strains, which clustered closer to the E strains. Based on the dendrogram, the E group was subdivided into three clusters (E1, E2, and E3). Strains within these subclusters did not correspond to any particular origin (Maui or Oahu) or any single collection date.

BOX-PCR fingerprint distribution. In general, all Dickeya strains isolated from an infected plant were of a single haplotype but multiple haplotypes were found within a field (Fig. 4). A and B haplotypes were found during the initial outbreak in 2003-04 from one field planted with propagative material originating from Costa Rica and Honduras (Fig. 4). These haplotypes were never found in Philippine propagative material. $\mathrm{C}$ haplotypes were found in adja-

Table 1. Strains of Dickeya sp. isolated from pineapple plants and water sources in Hawaii ${ }^{\mathrm{a}}$

\begin{tabular}{|c|c|c|c|c|c|c|c|}
\hline A number & Other ID & $\begin{array}{c}\text { Collection } \\
\text { year }\end{array}$ & $\begin{array}{l}\text { Origin of strain or } \\
\text { propagule }\end{array}$ & MAb 19c2g4 & MAb 97c1f8 & $\begin{array}{l}\text { BOX-PCR } \\
\text { haplotype }^{c}\end{array}$ & Pathogenicity \\
\hline 5264 & $1-2 \mathrm{~A}$ & 2003 & Costa Rica & - & + & $\mathrm{A}$ & - \\
\hline 5268 & $1-5 B$ & 2003 & Costa Rica & - & + & A & - \\
\hline 5305 & $3-4$ & 2004 & Honduras & - & + & A & w \\
\hline 5310 & $3-9$ & 2004 & Honduras & + & + & B & + \\
\hline 5272 & $1-9 \mathrm{C}$ & 2003 & Costa Rica & + & + & $\mathrm{C} 1$ & + \\
\hline 5292 & $7-1$ & 2004 & Costa Rica & + & + & $\mathrm{C} 1$ & + \\
\hline 5307 & $3-6$ & 2004 & Honduras & + & + & $\mathrm{C} 2$ & + \\
\hline 5376 & 14-1-1A & 2006 & Philippines & - & + & D1 & - \\
\hline 5383 & $14-3-1 \mathrm{~F}$ & 2006 & Philippines & + & + & D1 & - \\
\hline 5385 & $14-4-1 \mathrm{~F}$ & 2006 & Philippines & + & + & D1 & - \\
\hline 5392 & $14-8-2 \mathrm{E}$ & 2006 & Philippines & + & + & D1 & w \\
\hline 5394 & $15-2-1$ & 2006 & Philippines & + & + & D2 & - \\
\hline 5395 & $16-3-1$ & 2006 & Philippines & + & + & D2 & - \\
\hline 5408 & $16-6-2 I$ & 2006 & Philippines & + & + & D2 & w \\
\hline 5410 & $16-8-1$ & 2006 & Philippines & + & + & D3 & + \\
\hline 5708 & $17-3-1$ & 2007 & Philippines & + & + & D2 & + \\
\hline 5709 & $17-3-2 \mathrm{~A}$ & 2007 & Philippines & + & + & D2 & $\mathrm{W}$ \\
\hline 5608 & $23-3-2$ & 2007 & Philippines & + & + & D3 & w \\
\hline 5609 & $23-5-1$ & 2007 & Philippines & + & + & D1 & + \\
\hline 5614 & $26-1$ & 2008 & Philippines & + & + & $\mathrm{C} 1$ & + \\
\hline 5623 & $29-5$ & 2008 & Philippines & + & + & $\mathrm{C} 1$ & - \\
\hline 5277 & $1-\# 17$ & 2003 & Irrigation ditch (Oahu) & - & + & UA & - \\
\hline 5428 & $16-12-2 \mathrm{~A}$ & 2006 & Reservoir (Oahu) & + & + & $\mathrm{E}$ & + \\
\hline 5432 & $16-12-3 X$ & 2006 & Reservoir (Oahu) & - & + & $\mathrm{E}$ & $\mathrm{W}$ \\
\hline 5459 & $17-1-1 \mathrm{~A}$ & 2007 & Reservoir (Oahu) & + & + & $\mathrm{E}$ & $\mathrm{w}$ \\
\hline 5461 & $17-1-2 \mathrm{~A}$ & 2007 & Reservoir (Oahu) & + & + & D1 & - \\
\hline 5468 & $17-2-3 \mathrm{C}$ & 2007 & Reservoir (Oahu) & + & + & D2 & + \\
\hline 5612 & $25-3-3 A$ & 2008 & Irrigation ditch (Maui) & + & + & $\mathrm{E}$ & - \\
\hline 5613 & $25-3-7$ & 2008 & Irrigation ditch (Maui) & + & + & $\mathrm{E}$ & + \\
\hline 5627 & $29-9-1 \mathrm{~A}$ & 2008 & Irrigation ditch (Oahu) & - & + & $\mathrm{E}$ & + \\
\hline 5629 & $29-9-3 \mathrm{C}$ & 2008 & Irrigation ditch (Oahu) & - & + & $\mathrm{E}$ & + \\
\hline 5648 & $29-7-1 \mathrm{C}$ & 2008 & Irrigation ditch (Oahu) & - & + & UA & - \\
\hline
\end{tabular}

${ }^{\mathrm{a}} \mathrm{MAb}=$ monoclonal antibody and $\mathrm{PCR}=$ polymerase chain reaction.

b Laboratory accession number.

${ }^{\mathrm{c}}$ Each unique DNA fingerprint pattern generated using the BOXA1R primer (28) considered a haplotype based on visual inspection. UA = unassigned.

d Symbols: $-=$ nonpathogenic strains, $+=$ virulent strains, and $\mathrm{w}=$ weakly virulent. 
cent fields with significant bacterial heart rot during the initial outbreak, in another field in 2006, and again in four separate fields in 2008. Strains with haplotype C1 were isolated each time. In contrast, strains with haplotype $\mathrm{C} 2$ were only isolated from Costa Rican and Honduran plant material in 2003-04. The D1 haplotype was found in plants from five different fields and one water source. This haplotype was prevalent during the first survey of 2006 but found only twice in 2007 (once from plant material and once from water) and once in 2008. Strains possessing the D2 haplotype were also found in five different fields and in one water source during the second survey of 2006 and throughout 2007 and 2008. The D3 haplotype was seen in one field in 2006 and two fields in 2007.

Strains with A, B, and C haplotypes were never isolated from water sources, whereas strains with D haplotypes (D1 and D2) were identified in both plants and water (Fig. 2, lanes 15 and 16). Strains with haplotypes falling into group E or that remained unclassified because of considerable deviation from other fingerprints were isolated only from irrigation water.

Reactivity with MAb 19c2g4 and MAb 97c1f8. Of the 32 Dickeya strains characterized in this study, $100 \%$ reacted with MAb 97c1f8 (Table 1). On the other hand, MAb 19c2g4 reacted with all strains with $\mathrm{B}$ and $\mathrm{C}$ haplotypes but not with group $\mathrm{A}$ strains. This MAb also reacted with one D1 strain and five of nine group E strains.

Pathogenicity. Two strains with the A haplotype were nonpathogenic and a third produced only light brown necrosis (Table 1). The haplotype B strain and four of the five haplotype C strains produced typical water-soaked lesions and blisters and were considered pathogenic. Virulence of strains from haplotypes D and E varied, some causing no symptoms while others produced light brown lesions or typical heart rot symptoms (Table 1).

\section{Discussion}

In the past, Hawaiian pineapple plantations have grown primarily the 'Smooth Cayenne' variety and produced their own propagative materials for replanting. A recent trend in consumer preferences for low-acid hybrids, however, led to some producers turning to alternate sources of planting stocks from Central America and Asia to meet an increase in market demand. There is evidence that some hybrid varieties such as 'Josapine,' which is popular in Malaysia and is a cross between a variety that is highly susceptible to bacterial heart rot and the fairly tolerant Smooth Cayenne, are more susceptible to bacterial heart rot (22). During the early to mid-2000s, thousands of hybrid propagules were imported into Hawaii from Central America and Asia, where pineapple heart rot was previously observed.

The Dickeya strains isolated from planting stock from Central America and Asia possessed similar yet distinguishable and reproducible BOX-PCR haplotypes, suggesting a multiple introduction theory rather than infection of a highly susceptible cultivar by local strains. This was supported by both visual assessments of DNA fingerprints on gels and dendrogram similarity data. As reported previously, the Central American stocks were infected with strains in BOX-PCR groups A, B, and C $(6,29)$. In the current study, it was determined that the Philippine material was also infected with the previously observed $\mathrm{C}$ group in addition to several new BOX-PCR haplotypes not seen in the Central American stock. At least one study from another group of researchers suggested the importance of local populations of Dickeya in bacterial heart rot epidemics (23). Dickeya strains from the soil were thought to play a role in the initiation of an outbreak at three geographically distinct sites in Malaysia planted with suckers originating from a single supplier. Several enterobacterial repetitive intergenic consensus (ERIC)-

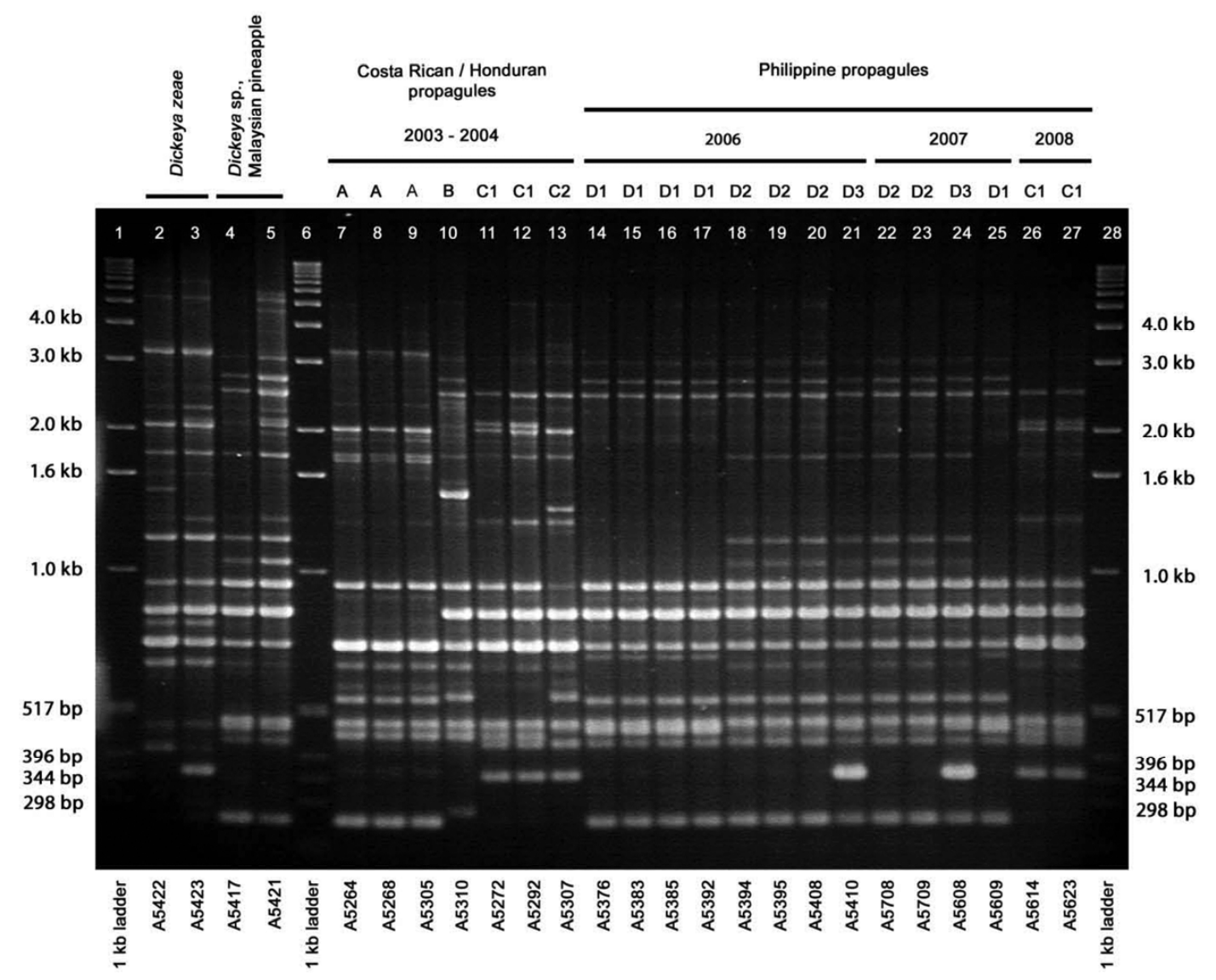

Fig. 1. Comparison of BOX-polymerase chain reaction (PCR) fingerprint patterns from Dickeya spp. Lanes 1, 6, and 28 contain 1-kb markers; lanes 2 and 3, reference strains of Dickeya zeae isolated on corn (Zea mays) from the United States and on pineapple from Martinique, respectively; lanes 4 and 5, reference Dickeya strains isolated from pineapple in Malaysia; lanes 7-27, strains isolated from pineapple plants originally imported as propagules from Costa Rica and Honduras (lanes 7-13) and the Philippines (lanes 14-27). Alphanumeric designations above lane numbers indicate respective BOX-PCR haplotypes. 
PCR patterns from three fields did not indicate the close clonal relationship which would have been expected had the inoculum originated from a single source (23). This is likely not the scenario in Hawaii, however, because certain common BOX-PCR fingerprints corresponded only to specific origins of the planting stock. Moreover, plant-isolated strains possessed fingerprint patterns distinct from most strains isolated from irrigation water sources.

In some locales, Dickeya strains are part of the natural bacterial microflora rather than contaminants from horticultural or agronomic enterprises (3). Norman et al. (17) found that the majority of rep-PCR fingerprints of $E$. chrysanthemi strains (now classified as Dickeya spp.) isolated from ornamental plants clustered separately from strains isolated from water sources. In their case, these $E$. chrysanthemi strains were obtained primarily from nursery retention ponds, leading them to conclude that these strains may be related to agricultural contamination rather than endemic populations of the pathogen. In Hawaii, BOX-PCR polymorphisms were observed between water strains collected at the different sites on Oahu and Maui; however, water strains appeared more similar to each other than to the plant-derived strains. The majority of the water from the surveyed irrigation ditches and reservoirs originated from mountain sources, giving support to the presence of natural, genetically distinct populations of waterborne Dickeya.
MAb 19c2g4 consistently differentiated the A haplotype from haplotypes $\mathrm{B}$ and $\mathrm{C}$ and the majority of the D haplotypes from plant materials. However, it did not consistently react with members with $\mathrm{E}$ haplotypes, which included the water strains. The A haplotype strains uniformly failed to react with MAb $19 \mathrm{c} 2 \mathrm{~g} 4$. These results are similar to those reported by Peckham et al. (19), who subsequently generated two new MAbs using A and $\mathrm{C} 1$ haplotype strains. In their study, MAb 2-A7 reacted with all haplotype $\mathrm{B}, \mathrm{C}$, and D strains but did not react with haplotype A or E strains, with the exception of one nonpathogenic $\mathrm{E}$ strain isolated from irrigation water (18). MAb 2-A7 reacted with two Malaysian strains (Dickeya spp.) isolated from pineapple in 1961 but not with six other Dickeya spp., which produced no symptoms after inoculation into pineapple (19). In our study, a second antibody (MAb 97c1f8) reacted with all Dickeya spp. tested but not $P$. carotovorum or other non-Dickeya spp. The reactivity pattern of this antibody was nearly identical to MAb 2-D11 generated by Peckham et al. $(18,19)$ which reacted with the reference strains representing six Dickeya spp. (24) and the pineapple strains but not with Pectobacterium and other non-Dickeya spp.

Bacterial heart rot symptoms were not observed during extensive surveys of a second pineapple plantation located on the island of Maui, and pineapple tissues from this plantation were also negative for Dickeya spp. However, two Dickeya strains with E haplotypes

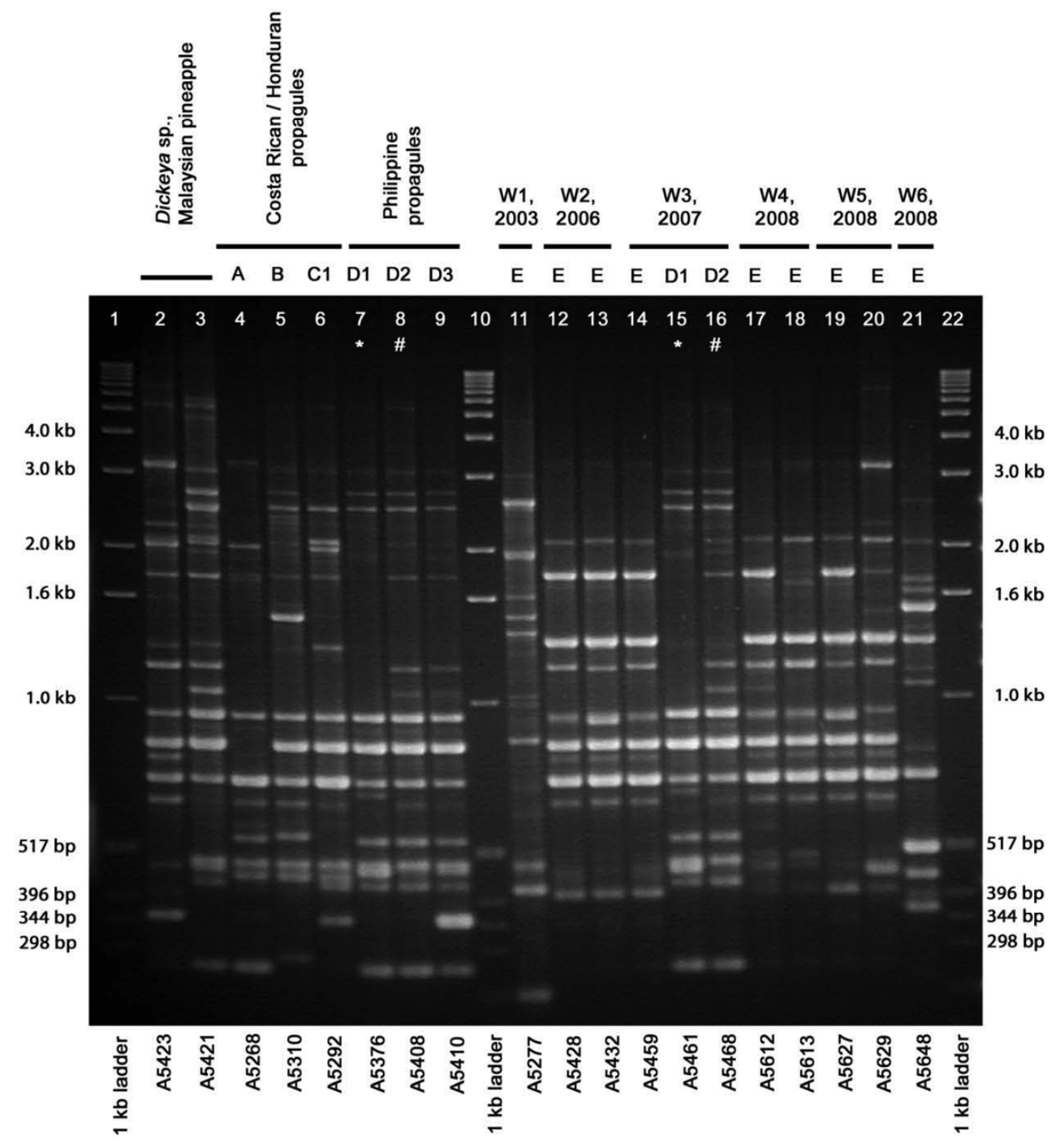

Fig. 2. BOX-polymerase chain reaction fingerprint patterns of Dickeya spp. isolated from pineapple plants and irrigation water. Lanes 1, 10, and 22 contain 1-kb markers: lanes 2 and 3, reference Dickeya strains isolated from pineapple plants from Malaysia; lanes 4-9, strains isolated on Oahu from pineapple plant materials originating from Costa Rica or Honduras (lanes 4-6) and the Philippines (lanes 7-9); lanes 11-21, strains isolated from irrigation ditches (lanes 11, 17-21) and a reservoir (lanes 12-16). Strains from irrigation water sources designated W1, W2, W3, W5, and W6 originated on Oahu. Strains from the water source designated W4 originated on Maui. Lanes marked with identical symbols_-for example, an asterisk (*) or a number sign (\#)-indicate identical fingerprint patterns. 
were isolated from an irrigation water sample on the Maui plantation. One strain was virulent after inoculation onto susceptible PRI 73-114 pineapple; the other was nonpathogenic. In a subsequent study, Marrero and Alvarez (12) found that the pineapple accession (73-050) grown extensively on Maui is highly tolerant to the pineapple-derived Dickeya strains from the Oahu outbreak. Although this information does not help elucidate the origins of the Oahu inoculum, it indicates that the Maui plants are less likely to succumb to the Dickeya populations currently infecting the Oahu plants.

Dickeya strains isolated from both plants and water could cause characteristic leaf symptoms following inoculation. This observa- tion was noted by other researchers as well. Of all E. chrysanthemi strains isolated from plants, nursery retention ponds, and lakes surveyed in a study in Florida, 99\% were pathogenic on dieffenbachia (17). Similarly, populations of Dickeya found in natural waterways and municipal water sources used to irrigate fields or nurseries were virulent on potato (8). In Hawaii, there were marked differences in the ability of the Dickeya strains to elicit typical leaf symptoms when inoculated into the susceptible pineapple PRI 73114. Although Peckham et al. (18) determined that disease severity was tied, in part, to seasonal variations in the plant material being inoculated, general conclusions could still be made. Strains from haplotypes $\mathrm{B}$ and $\mathrm{C}$ caused typical water-soaked blisters whereas

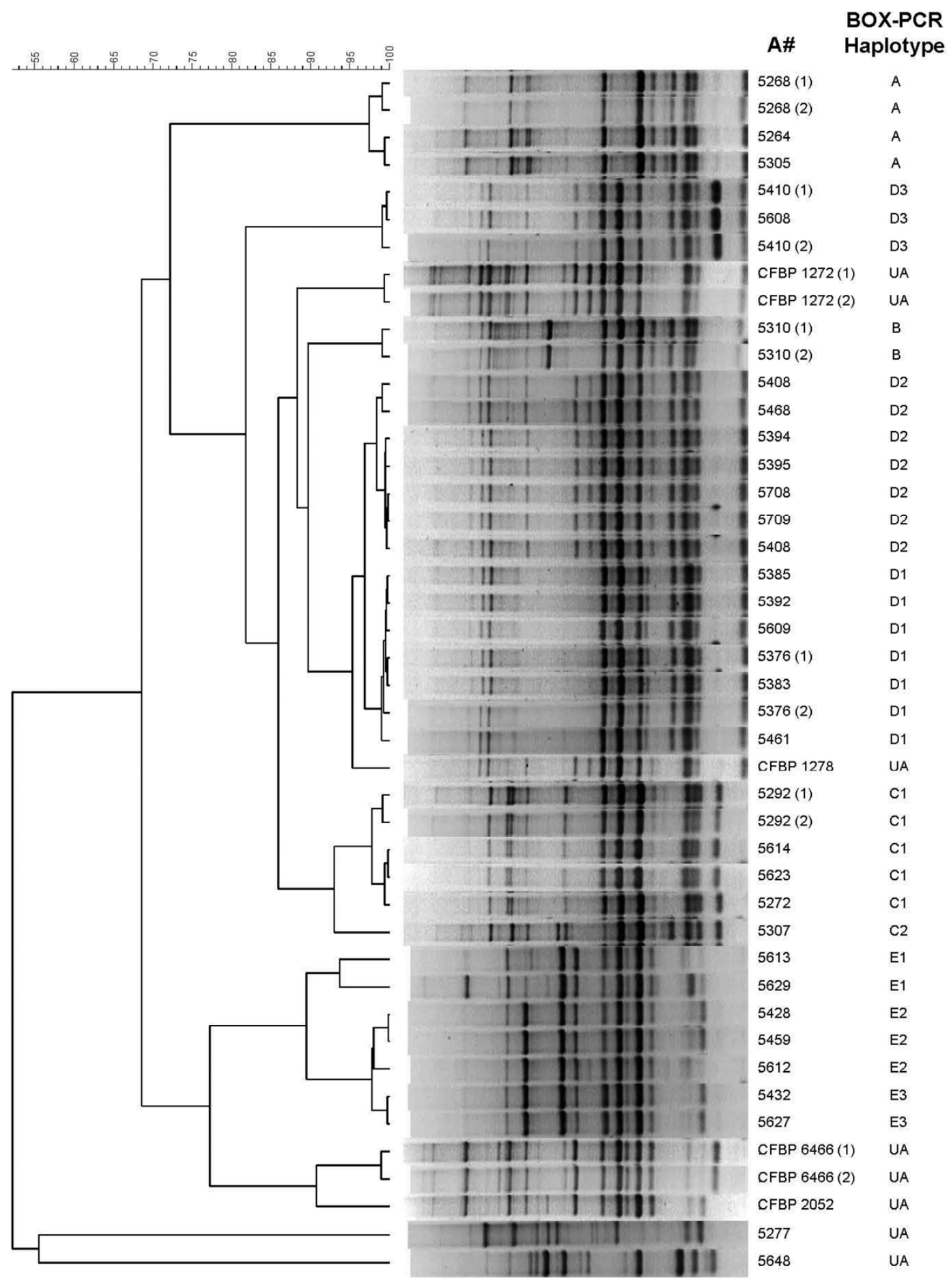

Fig. 3. Dendrogram based on BOX-polymerase chain reaction (PCR) fingerprint similarity between Dickeya strains from pineapple plants and irrigation water. Strain numbers followed by numbers in parentheses indicate that fingerprints originated from two separate gels. Reference strains CFBP 1278, CFBP 1272, CFBP 2052, and CFBP 6466 were not assigned haplotypes and are designated unassigned (UA). 
those in haplotype A showed weak reactions, if any. Haplotype D strains were not as virulent in pathogenicity tests and only about half of the haplotype E strains elicited typical water-soaked leaf blisters in inoculation assays. Because the initial symptoms observed during the outbreak were characteristic of a systemic infection (i.e., water-soaking of leaves from the base toward the tip followed by apical collapse) rather than a localized one, results from attached leaf assays may not be completely indicative of a strain's pathogenicity or virulence by its more natural mode of infection. This method did, however, give an idea of the pathogenicity potential of the haplotypes within a minimal time frame. It also allowed us to determine that $\mathrm{E}$ haplotype strains from irrigation water had the potential to infect plants in the field but did not appear to be doing so, strengthening the case for the inoculum introduction theory.

Haplotype distribution in fields varied during successive surveys. Notably, strains with $\mathrm{A}, \mathrm{B}$, and $\mathrm{C} 2$ haplotypes were only isolated from plants during the initial survey of the 2003-04 outbreak, whereas the $\mathrm{C} 1$ haplotype was isolated from plants in the initial and subsequent surveys. The D haplotypes were first found in 2006 in fields planted with Philippine propagules as well as from irrigation water sources. In contrast, strains with haplotype E were only isolated from water and were never isolated from field plants, although about half of them caused lesions in pathogenicity assays. The origin of any of the strains, whether from local environmental sources or from imported stocks, has not yet been established despite the strong evidence that strains from imported planting stocks are clearly different from those found in local water sources. Both scenarios have been proposed for diseases of other hosts and, therefore, are plausible hypotheses: infection by natural populations in potato (3) and infection by contaminating populations in ornamentals (17). Tsror et al. (26) attributed an outbreak of slow wilt of potato in Israel to infected seed potato imported from the Netherlands by comparing results from rep-PCR and biochemical assays of known strains isolated from Dutch seed potato tubers to strains isolated during their outbreak. Data collected and the trends observed during our surveys strongly suggest that the Hawaiian disease outbreak originated from imported planting stocks, similar to the potato outbreak in Israel, rather than an endemic population of Dickeya spp. However, this cannot be unequivocally proven without genomic comparisons with Dickeya cultures isolated directly from pineapple plants in Central America and the Philippines.

A recent phylogenetic analysis comparing Dickeya strains isolated from pineapple in Hawaii with reference strains of all Dickeya spp. (15) corroborates the BOX-PCR results presented in this study. The placement of pineapple-derived Dickeya strains in a close, yet distinct, phylogenetic clade from Dickeya isolated from irrigation water, as well as $D$. zeae reference strains, with multilocus sequence analysis is consistent with the groupings seen in the dendrogram of the BOX-PCR haplotypes. BOX-PCR haplotypes A through D, observed from strains isolated from pineapple, formed a clade with Malaysian pineapple reference strains (CFBP 1272 and 1278) whereas E haplotypes, observed with irrigation water strains, formed a clade with the unassigned haplotypes of $D$. zeae reference strains (CFBP 2052 and 6466). As previously noted, the assignment of pineapple-derived strains to a species of Dickeya has yet to be determined even though they form a larger clade with well characterized representatives of D. zeae (15). Additional studies are underway to obtain gene sequence data from Dickeya strains of pineapple from Central America and the Philippines as well as additional strains isolated from subsequent surveys on Oahu to determine the clonal relationships and geographic origins of the pineapple bacterial heart rot disease in Hawaii $(13,14)$. DNA-DNA hybridization also will be performed to assign a taxonomic designation to Dickeya spp. isolated during this outbreak.

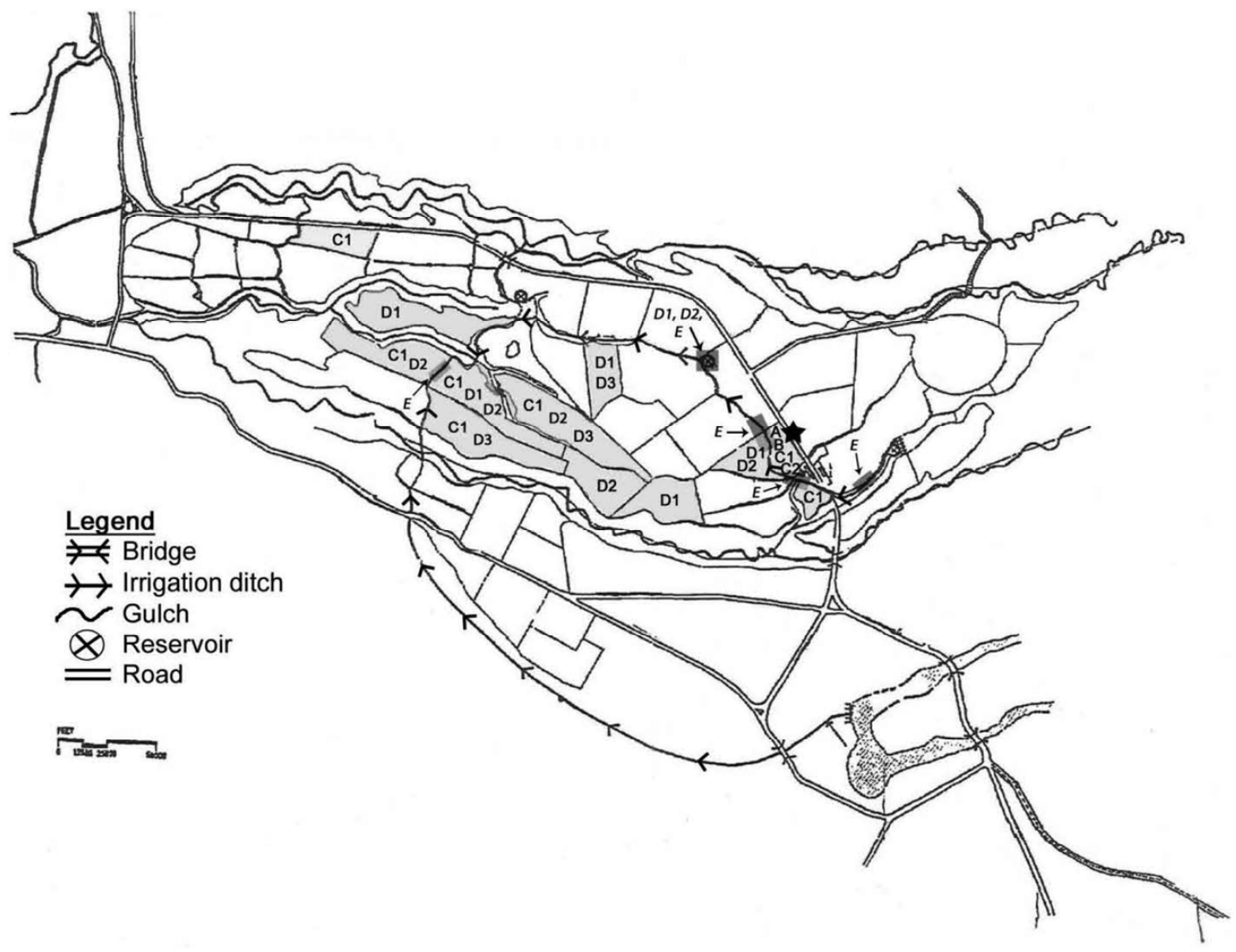

Fig. 4. Map of the pineapple plantation on Oahu where the bacterial heart rot survey occurred from 2003 to 2008 . The original field from which Dickeya strains were isolated from Costa Rican and Honduran plant propagules is to the immediate left of the star symbol ( $\star$ ). Fields from which Dickeya strains were recovered during 2005 to 2008 are shaded in light gray. Sampling sites where irrigation water sources yielded strains of Dickeya are marked with dark gray rectangles. BOX-polymerase chain reaction haplotypes recovered from the individual fields and water sources are noted. 


\section{Acknowledgments}

This research was funded by a grant through the United States Department of Agriculture Cooperative State Research, Education, and Extension Service Tropical/Subtropical Agricultural Research Program (award number 200934135-20114), Project Number HAW01912-09G. We thank J. Berestecky (Kapiolani Community College) for generating the MAbs used in this study, and F. Louws and S. A. Seehaver (North Carolina State University) for kindly assembling the BOX-PCR dendrograms.

\section{Literature Cited}

1. Bradbury, J. F. 1986. Guide to Plant Pathogenic Bacteria. CAB International, Wallingford, UK.

2. Brady, C. L., Cleenwerck, I., Denman, S. Venter, S. N., Rodríguez-Palenzuela, P., Coutinho, T. A., and DeVos, P. 2012. Proposal to reclassify Brenneria quercina (Hildebrand and Schroth 1967) Hauben et al. 1999 into a new genus, Lonsdalea gen. nov., as Lonsdalea quercina comb. nov., descriptions of Lonsdalea quercina subsp. quercina comb. nov., Lonsdalea quercina subsp. iberica subsp. nov. and Lonsdalea quercina subsp. britannica subsp. nov., emendation of the description of the genus Brenneria, reclassification of Dickeya dieffenbachiae as Dickeya dadantii subsp. dieffenbachiae comb. nov., and emendation of the description of Dickeya dadantii. Int. J. Syst. Evol. Microbiol. 62:1592-1602.

3. Cother, E. J., Bradley, J. K., Gillings, M. R., and Fahy, P. C. 1992. Characterization of Erwinia chrysanthemi biovars in alpine water sources by biochemical properties, GLC fatty acid analysis and genomic DNA fingerprinting. J. Appl. Bacteriol. 73:99-107.

4. Food and Agriculture Organization of the United Nations. 2009. FAOSTAT. http://faostat.fao.org/site/291/default.aspx

5. Hauben, L., Moore, E. R., Vauterin, L., Steenackers, M., Mergaert, J., Verdonck, L., and Swings, J. 1998. Phylogenetic position of phytopathogens within the Enterobacteriaceae. Syst. Appl. Microbiol. 21:384-397.

6. Kaneshiro, W. S., Burger, M., Vine, B. G., de Silva, A. S., and Alvarez, A. M. 2008. Characterization of Erwinia chrysanthemi from a bacterial heart rot of pineapple outbreak in Hawaii. Plant Dis. 92:1444-1450.

7. Krause, B. H. 1948. Anatomy of the vegetative organs of the pineapple, Ananas comosus (L.) Merr. Bot. Gaz. 110:159-217.

8. Laurila, J., Ahola, V., Kehtinen, A., Joutsjoki, T., Hannukkala, A., Rahkonen, A., and Pirhonen, M. 2008. Characterization of Dickeya strains isolated from potato and river water samples in Finland. Eur. J. Plant Pathol. 122:213-225

9. Li, X., Nie, J., Ward, L. J., Nickerson, J., and De Boer, S. H. 2011. Development and evaluation of a loop-mediated isothermal amplification assay for rapid detection and identification of Pectobacterium atrosepticum. Can. J. Plant Pathol. 33:447-457.

10. Louws, F. J., and Cuppels, D. A. 2001. Molecular techniques. Pages 321337 in: Laboratory Guide for Identification of Plant Pathogenic Bacteria, 3rd ed. N. W. Schaad, J. B. Jones, and W. Chun, eds. American Phytopathological Society, St. Paul, MN.

11. Ma, B., Hibbing, M. E., Kim, H.-S., Reedy, R. M., Yedidia, I., Breuer, J., Breuer, J., Glasner, J. D., Perna, N. T., Kelman, A., and Charkowski, A. O. 2007. Host range and molecular phylogenies of the soft rot enterobacterial genera Pectobacterium and Dickeya. Phytopathology 97:1150-1163.

12. Marrero, G., and Alvarez, A. M. 2011. Hawaiian strains of Erwinia chrysanthemi (Dickeya sp.) associated with pineapple heart rot disease. Pineapple News 18:57-59.

13. Marrero, G., Kaneshiro Sueno, W., De Silva, A. S., and Alvarez, A. M. 2010. Insights into the introduction of bacterial heart rot of pineapple to Hawaiian plantations on the basis of molecular and biochemical analyses. (Abstr.) Phytopathology 100:S78.

14. Marrero, G., Schneider, K. L, and Alvarez, A. M. 2009. Relationships between Dickeya species and strains from heart rot of pineapple based on sequence comparison of $d n a J$, gyrB, dnaA, and $\operatorname{recN}$ genes. (Abstr.) Phytopathology 99:S80.
15. Marrero, G., Schneider, K. L., Jenkins, D. M., and Alvarez, A. M. 2013. Phylogeny and classification of Dickeya based on multilocus sequence analysis. Int. J. Syst. Evol. Microbiol. 63:3524-3539.

16. Nassar, A., Darrasse, A., Lemattre, M., Kotoujansky, A., Dervin, C., Vedel, R., and Bertheau, Y. 1996. Characterization of Erwinia chrysanthemi by pectinolytic isozyme polymorphism and restriction fragment length polymorphism analysis of PCR-amplified fragments of pel genes. Appl. Environ. Microbiol. 62:2228-2235.

17. Norman, D. J., Yuen, J. M. F., Resendiz, R., and Boswell, J. 2003. Characterization of Erwinia populations from nursery retention ponds and lakes infecting ornamental plants in Florida. Plant Dis. 87:193-196.

18. Peckham, G., D., de Silva, A., Berestecky, J. M., and Alvarez, A. M. 2010. Correlation between antibody-binding properties and seasonal disease severity indices of Dickeya sp. that cause bacterial heart rot of pineapple. (Abstr.) Phytopathology 100:S98.

19. Peckham, G. D., Kaneshiro, W. S., Luu, V., Berestecky, J. M., and Alvarez, A. M. 2010. Specificity of monoclonal antibodies to strains of Dickeya sp. that cause bacterial heart rot of pineapple. Hybridoma 29:383-389.

20. Rohrbach, K. G., Leal, F., d'Eeckenbrugge, G. C. 2002. History, distribution and world production. Pages 1-12 in: The Pineapple: Botany, Production, and Uses. D. P Bartholomew, R. E. Paull, and K. G. Rohrbach, eds CABI Publishing, Cambridge, MA.

21. Rohrbach, K. G., and Schmitt, D. 2003. Diseases of Pineapple. Pages 443 464 in: Diseases of Tropical Fruit Crops. R. C. Ploetz, ed. CABI Publishing, Cambridge, MA.

22. Rozeita, L., and Kogeetha, R. 2010. Screening of MARDI's Josapine somaclonal variation in the field for selections that are BHR resistant or tolerant. Pineapple News 17:26.

23. Sahilah, A. M., Rozeita, L., Umi Kalsum, M. S., and Son, R. 2008. Typing of Erwinia chrysanthemi isolated from Josapine pineapple in Malaysia using antimicrobial susceptibility, plasmid profiles, ERIC-PCR and RFLP analysis. Int. Food Res. J. 15:273-280.

24. Samson, R., Legendre, J. B., Christen, R., Fischer-Le Saux, M., Achouak, W., and Gardan, L., 2005. Transfer of Pectobacterium chrysanthemi (Burkholder et al. 1953) Brenner et al. 1973 and Brenneria paradisiaca to the genus Dickeya gen. nov. as Dickeya chrysanthemi comb. nov. and Dickeya paradisiaca comb. nov. and delineations of four novel species, Dickeya dadantii sp. nov., Dickeya dianthicola sp. nov., Dickeya dieffenbachiae sp. nov. and Dickeya zeae sp. nov. Int. J. Syst. Evol. Microbiol. 55:1415-1427.

25. Toth, I. K., van der Wolf, J. M., Saddler, G., Lojkowska, E., Helias, V., Pirhonen, M., Tsror, L., and Elphinstone, J. G. 2011. Dickeya species: an emerging problem for potato production in Europe. Plant Pathol. 60:385399.

26. Tsror, L., Erlich, O., Lebiush, S., Hazanovsky, M., Zig, U., Slawiak, M. Grabe, G., van der Wolf, J. M., and van de Haar, J. J. 2009. Assessment of recent outbreaks of Dickeya sp. (syn. Erwinia chrysanthemi) slow wilt in potato crops in Israel. Eur. J. Plant Pathol. 123:311-320.

27. van der Wolf, J. M., Nijhuis, E. H., Kowalewska, M. J., Saddler, G. S., Parkinson, N., Elphinstone, J. G., Pritchard, L., Toth, I. K., Lojkowska, E., Potrykus, M., Waleron, M., de Vos, P., Cleenwerck, I., Pirhonen, M., Garlant, L., Hélias, V., Pothier, J. F., Pflüger, V., Duffy, B., Tsror, L., and Manulis, S. 2013. Dickeya solani sp. nov., a pectinolytic plant pathogenic bacterium isolated from potato (Solanum tuberosum). Int. J. Syst. Evol. Microbiol. Online publication. doi:10.1099/ijs.0.052944-0

28. Versalovic, J., Schneider, M., de Bruijn, F. J., and Lupski, J. R.1994. Genomic fingerprinting of bacteria using repetitive sequence-based polymerase chain reaction. Methods Mol. Cell Biol. 5:25-40.

29. Vine, B., Burger, M., Kaneshiro, W., de Silva, A., and Alvarez, A. 2005. Molecular characterization of bacterial strains to investigate the origin of pineapple heart rot disease in Hawaii. (Abstr.) Phytopathology 95:S107.

30. Weisburg, W. G., Barns, S. M., Pelletier, D. A., and Lane, D. J. 1991. 16S ribosomal DNA amplification for phylogenetic study. J. Bacteriol. 173:697703. 